\title{
O FLUIR DO POEMA EM PROSA DE MIA COUTO
}

\author{
THE FLOW OF THE PROSE \\ POEM OF MIA COUTO
}

Carlos Roberto dos Santos Menezes*

\section{RESUMO}

O presente artigo busca elucidar a filosofia de composição de Mia Couto através da estória "Nas águas do Tempo". Nossa viagem se inicia ao concebermos esta narrativa como um poema em prosa, em que iremos percorrer algumas formas composicionais utilizadas pelo escritor moçambicano. Pretendemos também demonstrar, através da sua consciência plasmadora, o ato de criação e o lugar da permanência das tradições moçambicanas.

PALAVRAS-CHAVE: Literatura Africana; Poema em prosa; Mia Couto.

\begin{abstract}
This article aims to clarify the creation process of Mia Couto through the story "Nas águas do tempo". Our journey begins to conceive this narrative as a prose poem in which we will explore some compositional forms used by the Mozambican writer. We also intend to show off through his formative consciousness the act of creation and the permanency's place of Mozambican traditions.
\end{abstract}

KEYWORDS: African Literature; Prose poem; Mia Couto. 
Repito mais uma vez: João Guimarães Rosa escreveu um romance, novelas e contos como se fizesse poesia. Sabendo que as palavras, além de significado, "têm canto e plumagem", e que as frases não são gaiolas, mas, sim, espaço e, no espaço, vôo. Não se quis discursivo, persuasivo, lógico. Preferiu ser expressivo, perscrutador e lúdico. Perseguiu uma prosa permanentemente emocional, uma prosa que fosse uma sequência de versos de verdade - e não apenas pela marcação de ritmo e pela contagem dos pés - , versos construídos com a força dos substantivos e o matrimônio da palavra que, juntas, se desbanalizam, readquirem a pureza semântica e os timbres primitivos, ou se mostram com novos valores que nelas não sabíamos.

(Alberto da Costa e Silva)

Estamos conscientes da extensão da epígrafe que escolhemos, mas cabe aqui explicá-la. Optamos por utilizar o primeiro parágrafo deste texto de Alberto da Costa e Silva, que abre a edição das Primeiras Estórias de Guimarães Rosa, da editora Nova Fronteira (2005), pois este fragmento nos serve como metonímia, propulsão, para adentrarmos no fazer poético de Mia Couto, já que não nos é novidade que o escritor moçambicano é exímio admirador da prosa roseana - inclusive, percebemos que suas narrativas, em certos pontos, se encontram em perfeita harmonia com as do escritor brasileiro.

Para além das semelhanças e diferenças entre as narrativas de ambos os escritores, nosso objetivo é focalizar o fazer poético de Mia Couto através do primeiro conto que abre o livro Estórias abensonhadas (1996), intitulado "Nas águas do tempo". E já observamos no título da estória que aqui será analisada o tom poético, expressivo, lúdico que se faz presente na prosa coutiana. Ao elucidar o leitor que o espaço literário será utilizado como criação de narrativas (estórias) que permeiam o espaço do onírico e sagrado (abensonhadas), o autor nos traz à tona a forma expressiva do seu discurso alinhada à tirania contra as formas pré-estabelecidas por meio do uso da prosa.

Estas estórias falam desse território onde nós vamos refazendo e vamos molhando de esperança o rosto da chuva, água abensonhada. Desse território onde todo homem é igual, assim: fingindo que está, sonhando que vai, inventando que volta. (COUTO, 1996, p. 8).

Como já mencionamos, a prosa coutiana é embebida de poesia tal qual a prosa roseana, como bem elucida Alberto da Costa e Silva. A mesma poesia que desde a sua origem esteve ligada à música e consequentemente às noções de ritmo. Mas o ritmo da frase, as relações de som e sentido, o sortilégio encantatório, as franjas de sugestões que superpõe ao conteúdo inteligível, são independentes da forma versificada. Sendo assim, 
desde o romantismo, todo o esforço da poesia tem sido o de explodir a atrela das convenções e dos preceitos que asfixiavam o impulso poético: métrica, rima, normas do verso clássico e do "estilo nobre", separação de gêneros, regras de gramática, de sintaxe, da lógica, etc.

O poema, advindo do verbo grego Poeiem (fazer plasmar, modelar), é algo composto, construído, per-feito. Concentração, totalidade de efeito, unidade são imprescindíveis à sua existência. Compacto, coeso, firmemente atado, o poema é um bloco de cristal irradiante que performa um jogo de múltiplos reflexos. É um universo de relações comparável a um contraponto musical. Comporta desenvolvimentos melódicos no plano horizontal e associações harmônicas no plano vertical, na medida que integra as diversas "vozes" do poema: sonoridades, sugestões, metáforas, palavras. As ideias e imagens de um poema não se encadeiam logicamente, mas vibram em si mesmas, constelam-se, inter-relacionam-se com os astros do céu.

A forma poética, o poema, que tanto lutou contra o convencionalismo da forma, tem na prosa, na escrita fluida, o seu processo destrutivo-construtivo. Já que a prosa aporta o desdém por moldes, codificações, preceitos e convenções; a plasticidade de criar a forma no próprio ato de desenvolvê-la, como um rio vai cavando o seu leito. Compreende também o dinamismo que quer o instável, o ímpar, o descontínuo, o dissonante, e confere maior liberdade ao ritmo e à sintaxe; traz consigo a maleabilidade apta a exprimir as mínimas nuances do homem e da realidade contemporâneas; a possibilidade de um vocabulário preciso, livre de interditos e censuras.

"Nas águas do tempo", assim como as outras estórias do livro, nasce exatamente desta junção do poema com a prosa, que por sua vez é uma criação voluntária, consciente e não algo amorfo e indefinido, a meio caminho entre a prosa e a poesia. Nasce de uma revolta contra as leis da métrica, da sintaxe, da linguagem, da prosódia. O poema em prosa abriga em si um princípio anárquico e destrutivo. Conta com toda revolta contra as leis vigentes sob pena de cair no informe e inorgânico e anular-se a si mesmo. É uma exigência inerente à poesia a de criar uma forma. Isso significa que o princípio anárquico e destrutivo, ele mesmo, impõe e exige o seu contrário: princípio orgânico e construtivo. O impulso desagregador corresponde ao uso da prosa; a força estruturante e equivalente à organização em poema.

O poema em prosa é uma arte "icárica” que quer transcender a linguagem, mas se serve desta linguagem, deseja romper com a forma pré-existente, e cria uma nova forma. Esta construção interna, que se resolve como uma complementariedade dialética, assinala o desequilíbrio entre o absoluto a que se aspira e os meios limitados para atingi-lo. Longe de se entregar aos delírios do inconsciente e da imaginação, o poeta em prosa medita, pondera e constrói: ele reflete criteriosamente sobre a sua arte e sobre as possibilidades da linguagem, incansavelmente perseguindo a descoberta de novas formas de expressão. Edgar Allan Poe (2011), por exemplo, nos 
revela o seu processo de reflexão ao construir seu poema "O corvo", no seu importante ensaio A filosofia da composição, na qual observa que

É bastante óbvio que todo enredo, que mereça este nome, deve ser elaborado até o fim antes que o autor escreva uma só linha. Só tendo em vista, constantemente, o final da história é que podemos dar a um enredo seu indispensável ar de consequência, ou causa, fazendo com que os incidentes, e especialmente o tom, apontem, o tempo todo, para o desenvolvimento da intenção. (POE, 2011, p. 17-18).

A filosofia composicional traz em si o desejo de encontrar uma língua - “Trouver une langue”, como disse Rimbaud -, de plasmar um dizer inédito, inaudito, que renove as possibilidades da língua. Mia Couto, por sua vez, se utiliza da língua portuguesa como matéria-prima poética, através de uma artesania verbal, com a qual explora as possibilidades latentes do idioma e reinventa-o por meio da morfologia e sintaxe contaminadas pelos falares moçambicanos. Desta forma, a recriação de neologismos, frases e a subversão de sentidos habituais apontam para a multiculturalização presente no seu país.

Embora o português seja recriado através de uma rede simbólica com os mitos e crenças moçambicanas, o autor não despreza totalmente as regras gramaticais do idioma oficial do país. Suas transgressões linguísticas buscam efeitos poéticos a fim de representar os ritos e crenças de Moçambique, escamoteados pelos anos de luta e sofrimentos pelos quais o país teve de passar.

Podemos observar o trabalho com a linguagem e os seus efeitos poéticos através da seguinte passagem do conto, na qual, cada neologismo traz dentro de si sua própria significação. A construção textual demonstra-se lucidamente calculada através das palavras que são arquitetonicamente elaboradas para trazerem sentido e harmonia ao universo poético da narrativa, na medida em que a linguagem se fecha pelo sentido e se abre para a expressão poética:

(...) Nosso barquito ficava ali, quieto, sonecando no suave embalo. $\mathrm{O}$ avô, calado, espiava as longínquas margens. Tudo em volta mergulhava em cacimbações, sombras feitas da própria luz, fosse ali a manhã eternamente ensonada. Ficámos assim, como em reza, tão quietos que parecíamos perfeitos. (COUTO, 1996, p. 10).

Percebemos que o universo criado por Mia Couto nesta estória, que nos serve de objeto de estudo, é um todo orgânico, autônomo, coeso e completo. Um universo fechado de relações, um microcosmos regido por um princípio articulador interno.

Para entendermos o princípio interno de articulação das estórias, nos convém atentarmos para a imagem de Plotino conhecida como "princípio de emanação", na qual as imagens da fonte e da árvore afiguram material e dinamicamente a passagem do uno ao múltiplo. A partir destas 
imagens podemos depreender o princípio de multiplicidade das estórias de Mia Couto, em que uma única semente se desdobra de formas diversas e sempre novas.

Imaginai uma fonte que não tem origem; ela doa sua água a todos os rios, mas não se esgota nessa doação. Ela permanece, tranquila, no mesmo nível. Os rios que dela promanam confundem inicialmente suas águas, antes de tomar seus cursos particulares, mas desde logo, cada um sabe aonde seu fluxo o levará. Imaginai agora a vida de uma árvore imensa. A vida circula através da árvore inteira, mas o princípio da vida permanece imóvel. Ele não se dissipa pela árvore, mas reside nas raízes. Este princípio fornece à planta a vida em suas múltiplas manifestações. Ele mesmo, porém, permanece imóvel, e, embora não seja múltiplo, é ele o princípio daquela multiplicidade. (PLOTINO, 1925, Enn. III, 8, 10).

É isto que distingue o poema em prosa da prosa poética, que por sua vez se configura como uma prosa imagética, na qual se pode escrever qualquer coisa, de romance a ensaio. A prosa poética é meio, não fim, em que o "poético" tem valor adjetivo. O poema em prosa, por outro lado, é um constructo rigoroso, um bloco, um objeto poético, no qual o todo preside à gênese e à organização de cada parte. $\mathrm{O}$ todo antecede e excede cada parte, como um princípio genético. Não podemos deixar de lado a advertência que abre o livro no qual o conto que estamos a analisar está inserido:

Estas estórias falam desse território onde vamos refazendo e vamos molhando de esperança o rosto da chuva, água abensonhada. Desse território onde todo homem é igual, assim: fingindo que está, sonhando que vai, inventando que volta. (COUTO, 1996, p. 8).

Através da advertência que já integra o plano metaficcional das narrativas que se seguem, Mia Couto já elucida para o leitor o embrião de suas estórias e do seu projeto poético de construção de um cosmos que se encontra no entre lugar da mágoa e da esperança. Lugar este que irá se desenvolver no espaço do real e do onírico - no qual se permite inventar e reinventar estórias. Este é, portanto, o fio condutor que irá unir cada narrativa que compõe esta obra. Muito embora estejamos a falar da totalidade a partir da advertência que precede os textos, temos de ter em mente que cada parte, ou seja, cada narrativa, tem fim em si mesma. Elas não visam nenhum objeto exterior, seja ele moral, filosófico, social ou didático. Contudo obedecem a uma teleologia interna, isto é, plenificam e consomem seus próprios projetos. Como cada estória é um verdadeiro poema em prosa, então elas podem admitir elementos descritivos e narrativos, mas os subordina ao todo, isto é, os coloca a co-laborar pelo conjunto. Qualquer componente exterior é "assimilado" ao grande organismo que é a obra ao recusar as digressões morais e filosóficas, desenvolvimentos explicativos e tudo o que arruíne a sua unidade e densidade. Sua força poética advém de uma síntese iluminadora. 
A narrativa "Nas águas do tempo", como estamos a ver, possui uma refinada estrutura literária. A narração não é feita na primeira pessoa gramatical, mas na primeira pessoa narrativa, ou seja, o neto, por ser aquele que narra, desdobra-se: eu-narrante (narrador) que assume a consciência da sua vida passada; e o eu-narrado (personagem) que se mostra sintonizado emocionalmente com a experiência imediatamente vivida.

A dualidade presente nesta forma narrativa permite tanto a narração do ponto de vista externo do narrador que já se encontra distanciado da representação dos acontecimentos anteriormente vividos, quanto do ponto de vista interno da personagem que nos transmite as suas emoções concomitantemente com a representação dos eventos experienciados. Esta estrutura que revela o anverso e o reverso da mesma pessoa, por meio da dualidade de perspectiva, imprime na narrativa um conhecimento autorreflexivo do sujeito.

Mia Couto elabora sua estória como uma forma de conhecimento, não mais como um mero relato de acontecimentos. Fato este que traz para a narrativa uma forma cognitiva complexa, na qual há a interação entre a consciência racional e a experiência emocional da personagem.

A estória é isomórfica, isso porque o conhecimento encontra-se tanto na forma quanto no conteúdo da narrativa. A forma, como já discutimos, é construída através da "poética da primeira pessoa narrativa"2. Já o conteúdo se desdobra por meio da viagem percorrida pelo neto e pelo avô. Esta viagem na perspectiva do mais velho representa a tentativa de manter viva uma tradição que se encontra em risco de extinção; para o mais novo ela representa o conhecimento da terra, das tradições do seu povo, assim como o autoconhecimento, por meio dos ensinamentos passados pelo seu avô. É por isso que a narrativa se torna dramática, já que revela as reações emocionais e as reflexões mentais das personagens.

Consciente de que toda viagem é uma forma de conhecimento, como bem nos lembra Walter Benjamin (2011), e que se não houver aprendizado durante o percurso feito pelas personagens, então a viagem não obtém o seu efeito, Mia Couto engenhosamente articula este pensamento com a forma narrativa adotada em sua estória. O neto, ou seja, o eu de agora não é mais como o eu de outrora, já que há uma distância temporal que os separa. Distância esta que lhe acarreta metamorfose existencial advinda do seu aprendizado. A partir deste novo eu, o ser de agora é capaz de narrar a sua viagem ao grande lago, lar das interditas criaturas. Com isso, o ensinamento mais precioso transmitido pela estória é o "reconhecimento de que a significação da realidade depende da subjetividade que a representa. Não há realidade em si mesma. Toda realidade é duplamente filtrada pela reflexão do narrador e pela emoção do protagonista" (SOUZA, 2010, p. 46). Por isso, o conhecimento adquirido pela personagem, tanto da experiência emocional quanto da consciência racional lhe permitem "funda[r] a cadeia de tradição, que transmite os acontecimentos de geração em geração" (BENJAMIN, 2012, p. 228), através da memória. 
Se observarmos o início da estória, percebemos que ela se inicia através da viagem, imagem simbólica a ser posta aos olhos do leitor. $\mathrm{O}$ artifício usado pelo autor encontra-se metonimicamente presente na imagem que o narrador homodiegético produz na primeira fala do seu relato: "Meu avô, nesses dias, me levava rio abaixo, enfiado em seu pequeno concho" (COUTO, 1996, p. 9). A imagem gerada pela linguagem, que inicialmente referia-se apenas ao sentido da viagem feita pelas personagens, na verdade é a concisão temática da narrativa. Com isso, percebemos de imediato o poder da linguagem - matéria-prima da construção narrativa - na medida em que a mesma, na sua capacidade sintética, é a geradora de uma única imagem que detém o sentido da estória.

Sendo a figura do mais velho aquela que possui autoridade e validade pela sabedoria que detém diante da possibilidade de extinção de uma tradição, se vê obrigada a iniciar uma jornada acompanhada de seu neto para tentar manter as memórias do povo e da terra vivas através das novas gerações. A viagem, portanto, é feita no sentido descendente do rio, rumo ao âmago da tradição conservada pelo avô que representa a resistência perante a morte das tradições advindas das destruições causadas pela guerra. O deslocamento feito pelas personagens nas águas do rio corresponde a uma descida às regiões subterrâneas. Podemos então conceber o curso desta viagem como sendo uma catábase, na qual a transdescendência catabática da personagem homodiegética a guia para a experiência do nada, o mergulho ao núcleo da sua alma. Viagem esta conduzida pelo avô: "no entanto, era ele quem me conduzia, um passo à frente de mim" (COUTO, 1996, p. 9). Entendemos, então, como catábase, a descida aos infernos, ou seja, a transposição do último horizonte da experiência humana. Experiência que culmina num segundo movimento, a transcendência do sujeito, em que o neto aprende e assimila os ensinamentos proferidos pelo seu avô durante a sua formação vital.

A peregrinação realizada pelas personagens rompe com o ceticismo do neto, que durante quase toda a narrativa nos confessa que acompanhava "sem convicção" o avô. Cabe ressaltar que mesmo havendo o ceticismo, o mais novo mantém o respeito pela figura do avô e por isso não lhe faz concessões. Lembramos também que o mais velho aconselha, e esta ação de aconselhar só é possível porque é intrínseca a ela a ação da sabedoria: "Sim, frente ao meu espanto ele [o avô] seguia um passo sabido" (Ibidem, p. 12). E o neto experiencia em vida os ensinamentos do avô. Desta forma, cabe ao mais velho pôr os seus ensinamentos em prática, realizando a travessia para o plano "fantasmático" da narrativa.

Atravessar a outra margem do rio significa transpor em vida os limiares da morte. Aquele que se põe a viajar através do rio busca atingir o seu último horizonte. Atingi-lo é morrer-se, nadificar-se. É o momento em que vislumbramos o instante poético da estória, em que testemunhamos a harmonia dos contrários em que o avô recusa a razão em detrimento do 
instante onírico que se ergue na narrativa; e o neto, por sua vez, congrega em si o afeto e o respeito pelo mais velho diante do embate entre o ceticismo e o espanto. Tais antíteses encontram-se em ambivalência e colaboram para o arroubo, o êxtase deste instante poético. Instante este que nos é narrado de forma exata, no qual o contexto psicológico não é imposto ao leitor, sendo este capaz de interpretar a estória como quiser.

A viagem dessas personagens ocorre no entrelugar do "real" e do onírico. Basta-nos fazermos alguns levantamentos de semas que denotem estes estados que permeiam a narrativa. Encontramos como afirmação do entrelugar expressões como "raspando o remo na correnteza", "o barquinho cabecinhava", "dia já crepusculando", "interditas criaturas", "entrevisto”; e como semas do onírico temos a presença constante do estado de sonolência, como a "ensonada", "tudo... se inventava de existir", "sonecando", "miragem”, etc. Inúmeros são os exemplos que podemos levantar para definirmos estes dois polos pungentes da narrativa.

Cabe-nos ressaltar que o entrelugar do "real" e do onírico está interligado pela presença constante do tempo e do espaço. O lago é o lugar onde "o nosso pequeno rio desaguava. Aquele era o lugar das interditas criaturas. Tudo o que ali se exibia, afinal, se inventava de existir" (Ibidem, p. 10). O entrelugar entre o rio e a margem funciona como o espaço do onírico, lugar no qual se pode inventar as criaturas que nele habitam, como por exemplo o próprio namwetxo, "o fantasma que surgia à noite, feito só de metades" (Ibidem, p. 11). Já o tempo - este que é indissociável do espaço - também caracteriza-se por estar entre o amanhã e o anoitecer, logo, é em estado crepuscular no qual a viagem é feita.

A imagem espaço-temporal do crepúsculo é a do tempo mítico, circular, instante suspenso que nos suscita a ideia de fim de um ciclo e início de outro, contrário ao tempo linear. Fato este que podemos entender, também, como uma revolução cósmica, social ou moral que ocorre no curso de uma viagem. A imagem do rio, por sua vez, é aquela que nos remete à fertilidade das formas através do fluir das suas águas, na qual suas correntes designam a morte e a vida. O lago, então, segundo Chevalier (2009), seria como o olho da terra por onde os habitantes do mundo podem ver os homens, os animais e as plantas. Sendo assim, as águas do tempo são uma totalidade que engloba como atualidade o presente, o passado e, além disso, o futuro como um horizonte de possibilidades. Mas se estamos a falar de tempo, rio e lago, nos é conveniente também falarmos da margem - que se caracteriza por ser o estado que existe para além do ser e do não-ser, que tanto é simbolizado pela “outra margem” como também pela água corrente.

A viagem, como já dissemos, é a forma pela qual o homem obtém conhecimento - por isso "quem viaja tem muito que contar" (BENJAMIN, 2012 , p. 214). As personagens do conto, por sua vez, se movimentam - viajam - por uma geografia que não nos é definida, descrita; portanto não é paisagem, logo não é conhecida, sendo um espaço novo que permite que 
ambos adquiram uma nova visão de mundo. Este espaço instaurado no plano fantasmático é o mesmo que abriga as "interditas criaturas", que trabalha a imaginação e por fim convida à ação, como nos elucida Bachelard (2008), e com nos lembra Carmen Lúcia Tindó Ribeiro Secco:

Habitar oniricamente o outrora é mais do que recuperá-lo pelas lembranças, é viver espaços desaparecidos sob as ruínas, resgatando fragmentos perdidos e soterrados das tradições. $(1999, \text { p. 393) })^{3}$.

O avô ao fazer a travessia para a outra margem escolhe o espaço do onírico como abrigo, e todo abrigo possui a ideia de casa, "o não-eu que protege o eu" (BACHELARD, 2008, p. 24). Sendo assim, a nova morada do mais velho é aquela que

abriga o devaneio, [e esta] casa protege o sonhador, a casa permite sonhar em paz. Só os pensamentos e as experiências sancionam os valores humanos. Ao devaneio pertencem valores que marcam o homem em sua profundidade. O devaneio tem mesmo um privilégio de autovalorização. Ele usufrui diretamente do seu ser. Então, os lugares onde se viveu o devaneio [a canoa, o lago, e a terceira margem] reconstituem-se por si mesmos num novo devaneio. É exatamente porque as lembranças das antigas moradas são revividas como devaneios que as moradas do passado são imperecíveis dentro de nós (Ibidem, p. 26).

O fim do ceticismo do neto é o fim último da catábase que visa inaugurar uma existência autêntica e a permanência de uma tradição. Sendo assim, a catábase feita pelo avô é uma forma de permanecer nas "águas do tempo" da memória ao fundir seu corpo com as águas do lago. E a terceira margem, a sua nova morada, é o derradeiro horizonte a partir do qual a vida é um salto para o desconhecido. Atravessá-la é atingir a plenitude do ser que se encontra consigo mesmo. O neto, por sua vez, é aquele que ultrapassou o horizonte da experiência humana, portanto não pode mais ser o mesmo que outrora foi e por isso nos é capaz de narrar a estória de sua viagem já metamorfoseado em outro.

E saltou para a margem, me roubando o peito no susto. $\mathrm{O}$ avô pisava os interditos territórios? Sim, frente ao meu espanto, ele seguia um passo sabido. A canoa ficou balançando, em desequilibrismo com o meu peso ímpar. Presenciei o velho a alojar-se com a discrição de uma nuvem. Até que, entre a neblina, ele declinou em sonho, na margem da miragem. Fiquei ali, com muito espanto, tremendo de um frio arrepioso. Me recordo de ver uma garça de enorme brancura atravessar o céu. Parecia uma seta trespassando os flancos da tarde, fazendo sangrar todo o firmamento. Foi então que deparei na margem, do outro lado do mundo, o pano branco. Pela primeira vez, eu coincidia com meu avô na visão do pano. Enquanto ainda me duvidava foi surgindo, mesmo ao lado da aparição o aceno do pano vermelho do meu avô. Fi- 
quei indeciso, barafundido. Então, lentamente, tirei a camisa e agitei-a nos ares. E vi: o vermelho do pano dele se branqueando, em desmaio de cor. Meus olhos se neblinaram até que se poentaram as visões. (COUTO, 1996, p. 12-13).

Torna-se clara a dialética entre a relação do mais novo e do mais velho na estória em questão. Dialética esta que as literaturas africanas abordam com frequência. Isto provém da necessidade de se preservar uma tradição da cultura africana. Tradição esta que com o advento da modernidade, com a implantação do capitalismo, com a força destrutiva do colonialismo e as guerras, está em perigo. A travessia do avô para a outra margem também simboliza a ideia de eternidade, que tem na "morte" a sua fonte primária. Com isso a literatura coutiana tenta sanar os perigos a que estão expostas as tradições, através da recriação do espaço e da cultura africana.

No caso desta estória de Mia Couto, essa tradição não é só recuperada através da dialética entre o mais novo e o mais velho, mas também na sua estrutura composicional. Se atentarmos para o narrador do conto, teremos a certeza de que estamos diante de um legítimo narrador, mais conhecido como narrador marinheiro, segundo Walter Benjamin (2012), cuja forma de narrar está fundada no ato de abominar o caráter informativo que o romance e a prosa moderna vêm adquirindo ao longo do tempo. Forma esta de preservar o legítimo ato de narrar associando-o a uma cultura com muitas estórias ainda por contar.

Há também um plano temático aparentemente em surdina que está atado ao eixo composicional, mas que também faz parte da narrativa. Falamos da tradição dos panos que o avô apresenta ao neto. Contudo, há uma outra tradição que a estória ensaia e não permite que se esgote. Esta narrativa escrita se aproxima da narrativa oral, na medida em que convoca para o plano da escrita marcas da oralidade do povo moçambicano; desta forma, a prosa coutiana se aproxima da narrativa ideal de Walter Benjamin, cujo grande "narrador tem sempre as suas raízes no povo" (BENJAMIN, 2012 , p. 231). Este trabalho faz da sua narrativa um verdadeiro tapete linguístico cujos bordados são espaços a serem percorridos pelo leitor.

Ler um texto, portanto, é decifrar a orquestração que o constitui, apreender em cada parte a presença dos vários temas, discernir o acordo - consoante ou dissonante - que eles compõem, em suma, seguir de ponta a ponta a elaboração do texto e o seu contraponto. Cabe ressaltar que o que conta não é cada elemento em si mesmo, mas o conjunto de relações arquitetônicas, a estrutura cósmica em que atuam; não apenas os conceitos e as imagens, mas também o arabesco de sons, do ritmo das frases, as significações simbólicas que transcendem o poema e significam além do que está expressamente dito. O poema diz dizendo e, sobretudo, não dizendo. O poema, portanto, é um todo altamente complexo, que institui novos vínculos, dentro e fora de si, no mundo poético e no mundo "real", ao agenciar elementos intelectuais (ideias e imagens) e componentes (palavras, sílabas, fonemas, letras). Com isso o autor constrói um objeto estético e ordena um 
mundo do qual é criador. Nenhum plano da narrativa é supérfluo (estrato fônico, morfológico, semântico, sintático), nenhuma palavra ou detalhe é irrelevante. Todos trabalham esteticamente, se inter-relacionam e concorrem para o efeito global, costurando-se indissoluvelmente, de modo que o todo é simultaneamente múltiplo e unitário. Sendo assim, podemos dizer que cada conto é uma parte do grande poema que é a obra escrita no fluir da prosa. Mia Couto então cria uma estória circular na qual a figura da morte preserva a ideia de eternidade da tradição ao carregar junto a poeticidade da terra e a força dos sonhos dos homens que a habitam.

\section{REFERÊNCIAS BIBLIOGRÁFICAS}

BACHELARD, Gaston. O direito de sonhar. Traduzido por José Américo et.all. 2a ed. São Paulo: DIFEL, 1986.

- A poética do espaço. Traduzido por Antonio de Pádua Danesi. $2^{\text {a }}$ ed. São Paulo: Martins Fontes, 2008.

BENJAMIN, Walter. Obras escolhidas I. Magia e técnica, arte e política. Traduzido por Sérgio Paulo Rouanet. $8^{\circ}$ ed. São Paulo: Brasiliense, 2012.

BERNARD, Suzanne. Le poème en Prose. De Baudelaire jusqu’à nos jours. Paris: Nizet, 1959.

CHEVALIER, Jean \& GHEERBRANT, Alain. Dicionário de símbolos. Rio de Janeiro: José Olímpio, 2009.

COUTO, Mia. Nas águas do tempo. In: Estórias abensonhadas. Rio de Janeiro: Nova Fronteira, 1996.

PLOTINO. Ennéade III. Traduzido por Émile Bréhier. Paris: Les Belles Lettres, 1925.

POE, Edgar Allan. A filosofia da composição. Traduzido por Léa Viveiros de Castro. 2a ${ }^{\mathrm{a}}$. ed. Rio de Janeiro: 7 Letras, 2011.

SECCO, Carmen Lúcia Tindó Ribeiro. Uma varanda para o índico. Entre lugar de sonhos, mitos e memórias.... In: SILVEIRA, Jorge Fernandes da. (Org.). Escrever a casa portuguesa. Belo Horizonte: UFMG, 1999. p. 385-398.

SILVA, Alberto da Costa e. Estas primeiras estórias. In: ROSA, João Guimarães. Primeiras Estórias. 1 ${ }^{\text {a }}$. ed. Especial. Rio de Janeiro. Nova Fronteira, 2005.

SOUZA, Ronaldes de Melo e. Ensaios de poética e hermenêutica. Rio de Janeiro: Oficina de Raquel, 2010. 


\section{NOTAS}

* Possui Licenciatura plena em Português-Literaturas pela Universidade Federal do Rio de Janeiro (2014); Bacharelado em Português-Literaturas pela Universidade Federal do Rio de Janeiro (2013); Pós-graduação Lato Sensu em Literatura Portuguesa e Literaturas Africanas Contemporâneas pela Universidade Federal do Rio de Janeiro; Mestrando em Letras Vernáculas no programa de Literatura Portuguesa e Africanas pela Universidade Federal do Rio de Janeiro (em andamento).

2 Para um estudo aprofundado recomenda-se a leitura do capítulo intitulado "A poética da narrativa de primeira pessoa" presente em livro de Ronaldes de Melo e Souza. (SOUZA, Ronaldes de Melo e. Ensaios de poética e hermenêutica. Rio de Janeiro: Oficina de Raquel, 2010. p. 31-53).

3 Apropriando-nos da citação que se segue deste comentário dito pela doutora Carmen Tindó temos um recorte de Walter Benjamin que nos elucida exatamente sobre este movimento de rememoração do neto de recontar a estória das viagens feitas com o avô: “.... o sonho participa do histórico. (...) Por ele, o indivíduo se comunica com seu próprio passado, que se cruza por mais de um ponto com a tradição coletiva, conseguindo salvar, do fundo dos tempos, momentos arcaicos significativos. (...) e, portanto, relevantes para o presente" (ROUANET, Paulo Sérgio. Édipo e o anjo. Rio de Janeiro: Tempo Brasileiro, 1981. p. 88-89). 